\title{
Performance Based Specification of Wood - Project CLICKdesign
}

\author{
Ed Suttie $^{1}$, Christian Brischke ${ }^{2}$, Eva Frühwald Hansson ${ }^{3}$, Stefania Fortino ${ }^{4}$, Jakub \\ Sandak $^{5}$, Magdalena Kutnik ${ }^{6}$, GryAlfredsen ${ }^{7}$, Christophe Lucas $^{8}$ and Eric Vieillemard ${ }^{9}$ \\ ${ }^{1}$ BRE, Garston, Watford, WD25 9XX, United Kingdom Ed.Suttie@bregroup.com \\ ${ }^{2}$ Abt. Holzbiologie und Holzprodukte, University of Göttingen, Büsgenweg 4, D-37077 Göttingen, \\ Germany christian.brischke@uni-goettingen.de \\ ${ }^{3}$ Structural Engineering, Lund University, Faculty of Engineering LTH, Box 118, SE-221 00 Lund, \\ Sweden eva.fruhwald_hansson@kstr.lth.se \\ ${ }^{4}$ Material Modeling and Ecodesign, VTT Ltd, PL 1000, FI-02044 Finland Stefania.Fortino@vtt.fi \\ ${ }^{5}$ InnoRenew CoE, Livade 6, 6310 Izola, Slovenia jakub.sandak@innorenew.eu \\ ${ }^{6}$ Technological Institute FCBA, Allées de Boutaut - BP 227, 33028 Bordeaux, France \\ Magdalena.Kutnik@fcba.fr \\ ${ }^{7}$ NIBIO, Norwegian Institute of Bioeconomy Research, Pb 115, NO-1431 Ås, Norway \\ Gry.Alfredsen@nibio.no \\ ${ }^{8}$ IRBI Institut de Recherche sur la Biologie de l'Insecte, Faculté des Sciences et Techniques, Avenue \\ Monge, Parc Grandmont, 37200 TOURS (France)France christophe.lucas@univ-tours.fr \\ ${ }^{9}$ Hygiene Office, 4 Rue Pelletier, 91320 Wissous, France ines.vieillemard@hygiene-office.fr
}

\begin{abstract}
This paper introduces the ForestValue research project CLICKdesign - delivering fingertip knowledge to enable service life performance specification of wood. The consortium is working on a primary innovation to move from the complex, fragmented and general to the easy-to-use, consolidated and specific by provision of a digital tool for specifiers. Other materials tackle this and provide designers and architects with software. The specification of performance of wood products is complex and fraught with inconsistency and requires use of multiple platforms for data, experience, standards and national recommendations. CLICKdesign will provide a tool that has within it the decades of research, the complexity of the standards specification systems and the variation of approach due to tradition, materials and culture across Europe and beyond. A simple tool for nonexpert public users will be available as well as a tool accessible to professional users that will be refined with industry to ensure relevancy and accelerate uptake and use.
\end{abstract}

Keywords: Durability-Based Design, Knowledge Transfer, Modelling, Performance, Service Life Planning.

\section{Introduction}

Concrete, steel and polymeric sectors deliver software to architects and students enabling easy performance-based specification and design. It also enables easy teaching of design best practice and informs learning gathered by product manufacturers. This does not happen for wood comprehensively in Europe, though specific initiatives e.g. UK Structural Timber 
Ed Suttie, Christian Brischke, Eva Frühwald Hansson, Stefania Fortino, Jakub Sandak, Magdalena Kutnik, Gry Alfredsen, Christophe Lucas and Eric Vieillemard

Association guidance (www.structuraltimber.co.uk) and the German Carpenter Association's Guideline on Building Facades, Terrace decking, and Balconies (BDZ 2011, 2016) do exist. In addition, technical specifications are integrated into increasingly used Building Information Modelling (BIM) and life cycle analysis (LCA) which includes service life data. Service life planning and performance classification are thus core issues in the building sector underpinning material/product specification and use. The absence of durability performance-based specification for wood is currently a limit of opportunity. Well-functioning 'performance models' are essential to predict the service life and functionality of buildings.

\section{Project CLICKdesign Context}

\subsection{Analysis of the Problem}

The established specification of wood is not performance based, historically standards refer to ineffectual terms to bridge the performance gap such as "a reasonable working life". Wood engineers utilising Eurocode 5 find the ineffectual language doesn't stand scrutiny and is of little value. Awareness of the cultural legacy of wood in construction around us, traditional uses and skills are constant reminders of the enduring possibility of wood if knowledge is applied, including knowledge of species and material qualities, knowledge of design details and construction skills, knowledge of local conditions, climatic or other challenges. This knowledge is fragmented, localised and in some cases difficult to analyse and use especially by non-wood

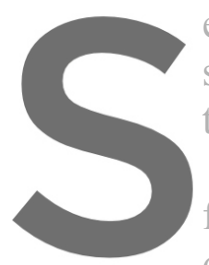
experts. This is the problem. The solution is to put this knowledge at the fingertips of the
specifier, in their language so inore can meet their ambitions to deliver low carbon construction. through performance based design with wood.

The existing decision first the suitability of durability of the chosentimbets st 2013), e.g. Use Class 4 for a fence post. EN 460: 1994 compares the requirements of Use Class

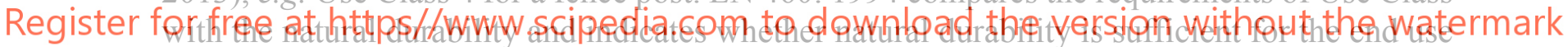

or whether preservative treatment is required. The European Standards related to specifying preservative treated timber, EN 351-1: 2007 and EN 351-2: 2007 require the specification to be written in terms of the end results of the treatment process i.e. penetration and retention in the wood of a preservative formulation found to be effective in a series of standard biological test methods laid down in EN 599-1: 2013. The specification of service life has evolved around the end results achieved following preservative treatment with service life referred to in an unquantified and ambiguous way using terms such as "reasonable working life" or "satisfactory performance". Standards that started to define desired service lives were a step in the right direction as the desire for information on performance of wood products grew in part buoyed by the application of LCA for construction products that pivots on their service life requirements. In Germany, France and UK there are national documents that set out frameworks for performance. In the UK the British Standard BS 8417: 2011 sets out a framework for specifiers to interpret the European standards and to base specifications on penetration and retention requirements linked to treated products and 'desired service life'.

The established wood species and treatment combination for a specific use class works well but has gaps that miss many additional opportunities for timber in construction through good 
Ed Suttie, Christian Brischke, Eva Frühwald Hansson, Stefania Fortino, Jakub Sandak, Magdalena Kutnik, Gry Alfredsen, Christophe Lucas and Eric Vieillemard

design detailing, the aesthetic performance, other tools to enhance natural properties, the impact of surface cracks on performance, surface roughness and the more subtle moisture dynamic of the wood material.

Different types of performance models have been established for various building materials but cannot be transferred to wood-based materials. For performance modelling of wood products biological agents need to be considered with particular attention for mould, decay fungi, termites and other insects as well as the strong societal values of regional vernacular, skills and traditions that only wood as a material brings. Different approaches to adequately reflect the influence of biotic and abiotic factors on the performance of wood have been reviewed and evaluated (Brischke and Thelandersson 2014) with respect to their usability in the building trade. They found that efforts in developing performance models for both fungal decay and mould growth have been intensified in recent years (e.g. MacKenzie et al., 2007, de Freitas et al. 2010, Viitanen et al., 2010, Isaksson et al., 2013, Niklewski et al., 2016). A high heterogeneity among the numerous attempts became visible, different strategies have been followed, and were roughly distinguished according to the respective objectives, governing variables (e.g. mass loss, strength loss, remaining strength, decay ratings, service life, aesthetic appearance), data sources and the resulting level of accuracy.

A framework of how exposure, dimension, design details, and the material-intrinsic ability to take up and release water can be linked to model the moisture risk in wood products and thus performance is the central need. First attempts prepared using various dosimeter models were made in previous European research projects, namely the WoodWisdom-Net projects WoodExter and DuraTB, the Swedish WoodBuild pro
PerformWOOD. Good progress has been made during recent y
performance prediction of wood-based components and struc
evident, the complexity of performance is still not captured in
The cross-links and interactions between exposure models,
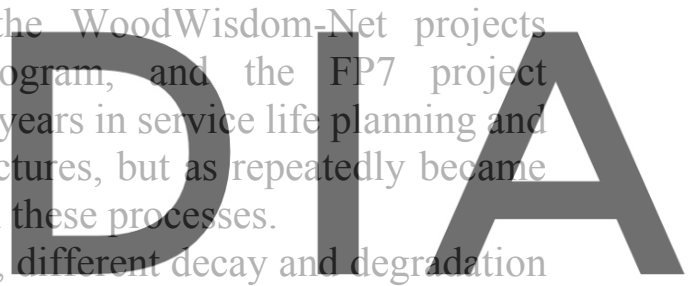

models, and material resistance models need to be deeply elaborated to allow their utilization

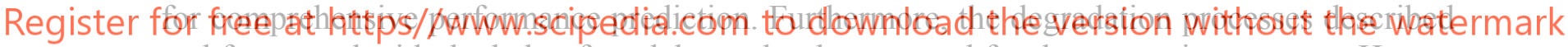
and forecasted with the help of models need to be assessed for the respective purpose. Hence, one needs to distinguish between aesthetic performance, functional performance, mechanical performance and other aspects of performance (Jones and Brischke 2017). In particular, the effect of fungal, bacterial or insect damage on the overall mechanical stability of wooden structures is still neither fully understood nor adequately modelled for engineering purposes.

\subsection{Beyond the State-of-the-Art}

Project CLICKdesign is shown schematically in Figure 1 and includes:

- Forecasting surface aesthetic changes developing the kinetic and/or intensity of such changes due to location, microclimate, architectural design and materials used.

- Development of damage spatial distribution significance on mechanical performance. Studying spatial distribution of fungal decay and its interaction with moisture transport and resulting gradients in buildings.

- Development of a termite/insect performance measure for the first time in Europe. 
Ed Suttie, Christian Brischke, Eva Frühwald Hansson, Stefania Fortino, Jakub Sandak, Magdalena Kutnik, Gry Alfredsen, Christophe Lucas and Eric Vieillemard

- Robust integrated performance classification based on the whole set of external parameters for the first time the foundation established for decay, material and integrity aspects, aesthetic limits and performance and termite/insect performance aspects.

- Providing a CLICKdesign tool that utilises European standards, the latest research findings and wood databases such as the IRG Durability Database (http://www.irgwp.com/durability) and puts it at the fingertips of specifiers and users. This will increase market confidence with users for selecting wood as a reliable product and enhance an optimised performance of timber in the built environment.

- Features wholly not integrated into specification now. The significant variations due to climate change present changes to exposure dose for wood products and the distribution and locations of wood destroying organisms e.g. termite risk zones in Europe.

- Inspiring new wood and wood-based products using the tool, supported by training outreach, and creating business opportunities for industries to innovate.

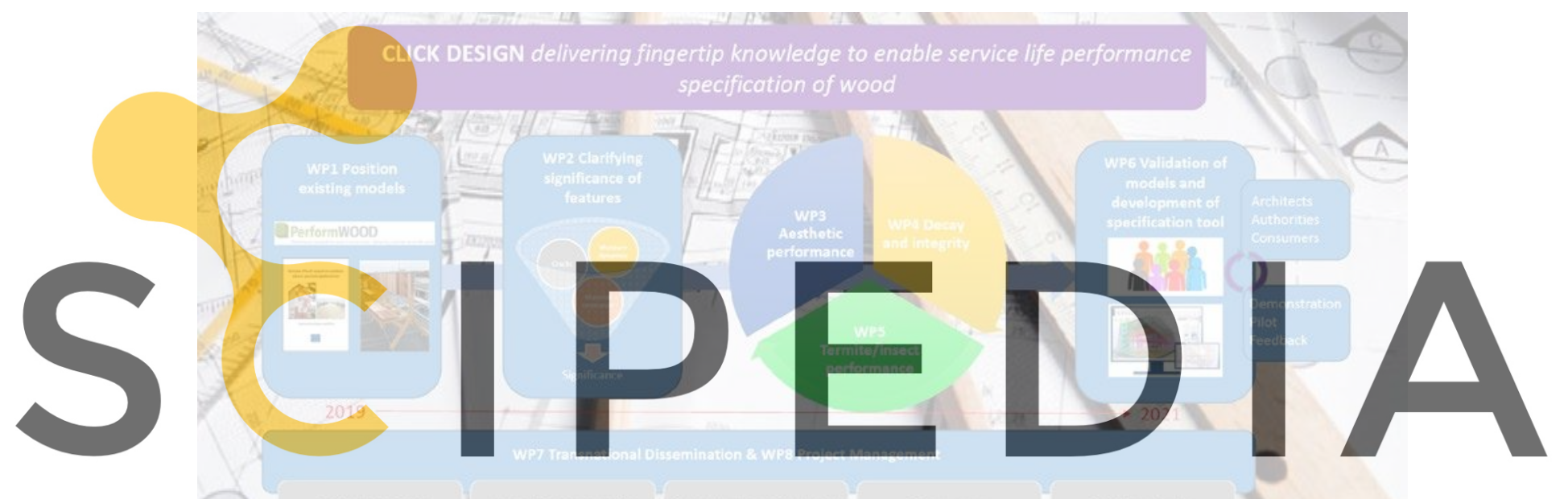

Register for free at https//www.scipedia.com to download the version without the watermark

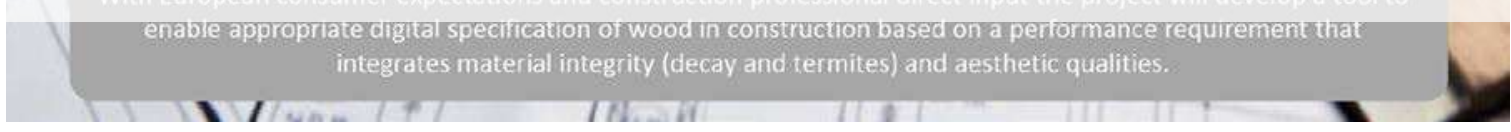

Figure 1. CLICKdesign project schematic showing proposed work packages.

The project builds on the foundations of the basic models and previous research work that comprise the existing knowledge landscape (Figure 2). Existing performance classification research has drawn together aspects of design detailing, climate and material and looked at forecasting performance compared to performance observed for construction products in buildings across Europe (PerformWOOD, WoodExter). Whilst this worked well as a rule of thumb it was missing two key features: aesthetics and insects.

In addition, modelling the effect of fungal decay on mechanical properties of wooden structures is being made, going beyond the simple limit states of previous work e.g. 'onset of decay' or 'failure'. Including these features has never been done before alongside the relatively mature model position that we have established in Europe for materials, strength, decay, design and performance. 
Ed Suttie, Christian Brischke, Eva Frühwald Hansson, Stefania Fortino, Jakub Sandak, Magdalena Kutnik, Gry Alfredsen, Christophe Lucas and Eric Vieillemard

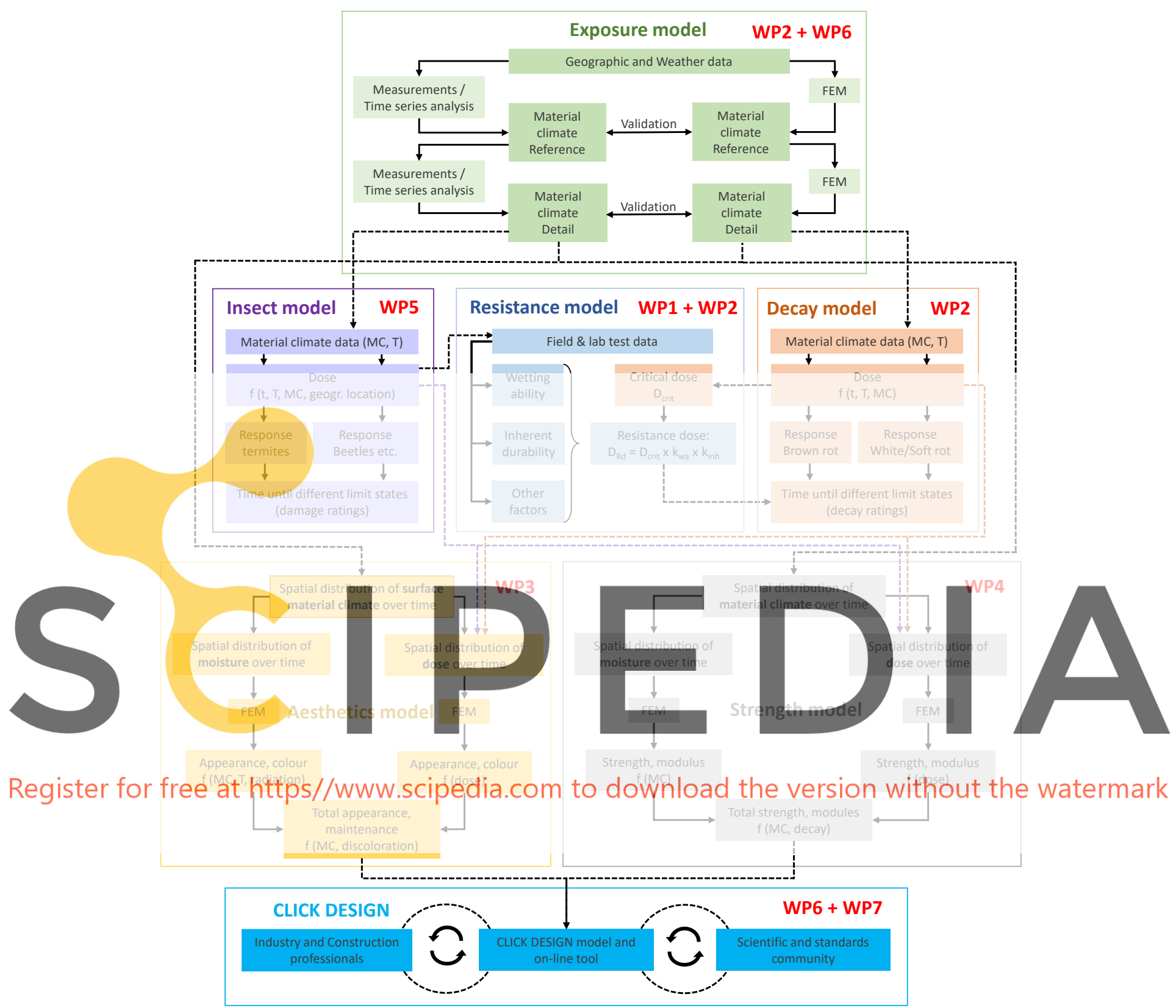

Figure 2. Different elements of performance modelling addressed in CLICKdesign.

For exterior cladding and other applications of wood and wood-based products the acceptance of changes in aesthetics (weathering, colour change, mould) is the key customer parameter (Gobakken 2009, Gellerich et al., 2017). Forecasting of surface changes in terms of discoloration, roughness, overall appearance is therefore indispensable and needs to be linked with other performance models. This is especially critical for Use Class 3 (outdoor aboveground) wood performance classification and for pan-European uptake. 
Ed Suttie, Christian Brischke, Eva Frühwald Hansson, Stefania Fortino, Jakub Sandak, Magdalena Kutnik, Gry Alfredsen, Christophe Lucas and Eric Vieillemard

Different parameters need to be taken into account in order to define the risk for a wooden element of being degraded by biological agents, including termites and other insects. Subterranean termites are widely distributed in warm climates across the countries of southern Europe, both in rural and in urban areas. The most serious harm caused by subterranean termites to buildings is the degradation of the wooden elements, in particular those ensuring the integrity of the building such as the timber frame, load-bearing elements and structural panels.

Key to the success for CLICKdesign is that the tool finds application across Europe's rich diversity of geographic, climatic and cultural regions. The integration of climatic conditions (meso, macro and micro) into the models is fundamental and one approach where this is being tackled. The weather through experiences in projects such as DuraTB and Woodlife are translatable into microclimate in the wood and its response. A relationship connecting climate parameters to the material climate makes it possible to analyse a wide range of regional climates through use of open meteorological databases such as ECMWF www.ecmwf.int. Dosimeter approaches developed to describe the interrelationship between material-climatic parameters (exposure dose), material-specific resistance (resistance dose) and wood degradation (response) can then be used to study the regional-specific performance. The same methodology is also be employed for predicting degradation by termites and other insects. For that purpose, input variables need to be different and will be sought from existing field test data and short-term resistance tests performed within CLICKdesign. Success will be possible using a structured approach that couples models and enables direct localisation for the user. In addition, factors that differ between countries and regions of Europe we are cognisant of fostering the different traditions of use of wdoc in cultural aspects toward

2.3 Project Facts
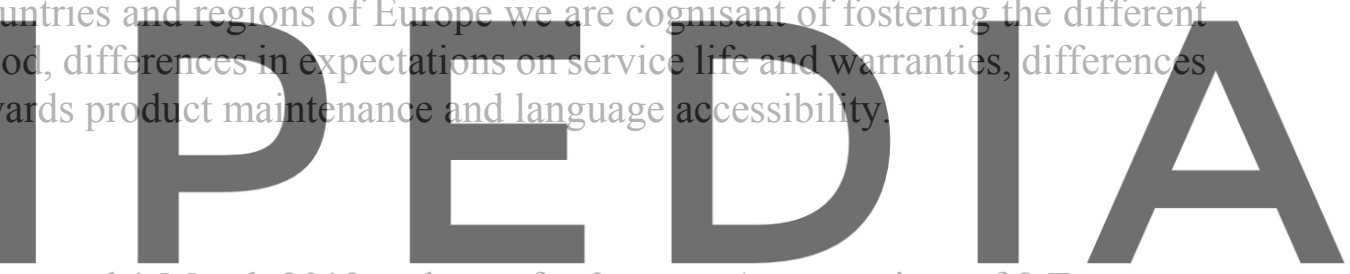

Project CLICKdesign started 1 March 2019 and runs for 3 years. A consortium of 8 European

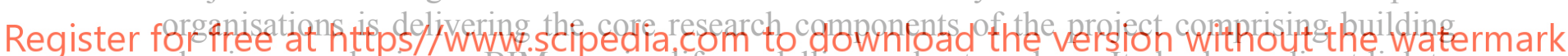
physics, wood science, BIM, service life modelling and entomology. It also has a direct link to the expert research team in FPI Innovations, Canada to look at global application and a diverse pan-European industry group of 18 members who will help pilot and bring together the modelled components of performance of wood in use to develop an open source tool.

\subsection{Project Highlights to Date}

Whilst additional DBMC papers (e.g. Digital transformation of biological processes and building design theory) are reporting on some of the detail a summary of highlights against work package (WP) are shown in Table 1.

\section{Conclusions}

The specification of performance of wood products is complex and fraught with inconsistency and requires use of multiple platforms for data, experience, standards and national recommendations. CLICKdesign will provide a tool that has within it the decades of excellent research, the complexity of the standards specification systems and the variation of approach due to tradition, materials and culture across Europe. The tool will be accessible to professional 
Ed Suttie, Christian Brischke, Eva Frühwald Hansson, Stefania Fortino, Jakub Sandak, Magdalena Kutnik, Gry Alfredsen, Christophe Lucas and Eric Vieillemard

users and will be refined with industry to ensure relevancy and accelerate its uptake and use. The project supports "fit for purpose" product specification and enables specifiers and users to understand the impact of their choices on performance.

Table 1. Summary of project CLICKdesign highlights up to November 2019.

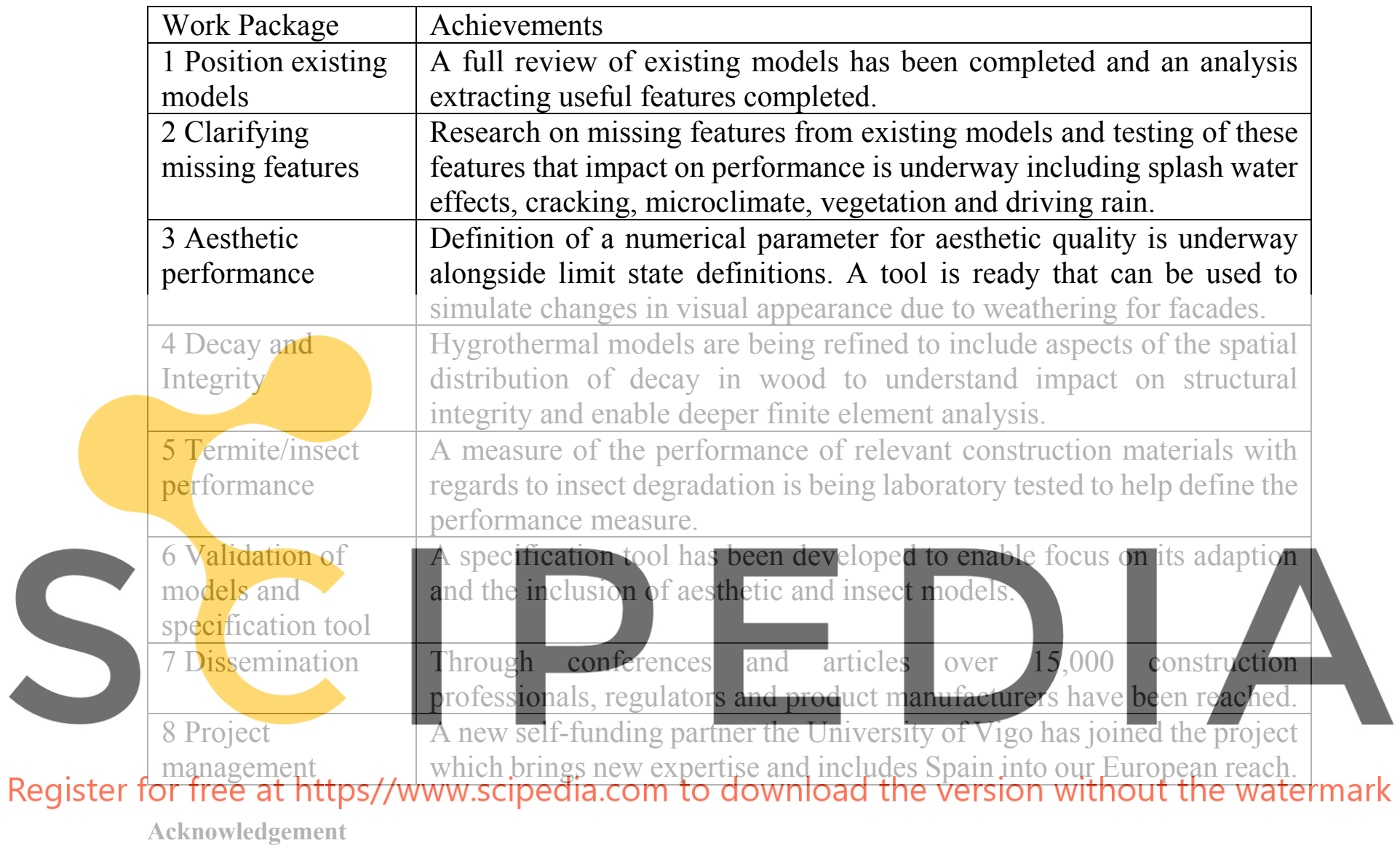

Project CLICKdesign is supported under the umbrella of ERA-NET Cofund ForestValue by the Ministry of Education, Science and Sport (MIZS) - Slovenia; The Ministry of the Environment (YM) - Finland; The Forestry Commissioners (FC) - UK; Research Council of Norway (RCN) -Norway; The French Environment \& Energy Management Agency (ADEME) and The French National Research Agency (ANR) - France; The Swedish Research Council for Environment, Agricultural Sciences and Spatial Planning (FORMAS), Swedish Energy Agency (SWEA), Swedish Governmental Agency for Innovation Systems (Vinnova) - Sweden; Federal Ministry of Food and Agriculture (BMEL) and Agency for Renewable Resources (FNR) - Germany. ForestValue has received funding from the European Union's Horizon 2020 research and innovation programme under grant agreement $\mathrm{N}^{\circ} 773324$.

\section{ORCID}

Ed Suttie: https://orcid.org/0000-0002-0938-3728

Christian Brischke: https://orcid.org/0000-0003-4652-825X

Eva Frühwald Hansson: https://orcid.org/0000-0003-2357-2135

Stefania Fortino: https://orcid.org/0000-0002-1613-6493

Jakub Sandak: https://orcid.org/0000-0001-9190-677X

Magdalena Kutnik: https://orcid.org/0000-0002-5522-5413

Gry Alfredsen: https://orcid.org/0000-0002-4560-9499 
Ed Suttie, Christian Brischke, Eva Frühwald Hansson, Stefania Fortino, Jakub Sandak, Magdalena Kutnik, Gry Alfredsen, Christophe Lucas and Eric Vieillemard

Christophe Lucas: https://orcid.org/0000-0003-2839-7583

\section{References}

Brischke, C. and Thelandersson, S. (2014). Modelling the outdoor performance of wood products -A review on existing approaches. Constr. Build. Mat. 66:384-397.

Brischke, C. and Meyer-Veltrup, L. (2016). Modelling timber decay caused by brown rot fungi. Mat. Struct. 49:3281-3291.

de Freitas, R.R., Molina, J.C. and Júnior, C.C. (2010). Mathematical model for timber decay in contact with the ground contact adjusted for the state of São Paulo, Brazil. Mat. Res. 13:151-158.

Foliente, G.C., Leicester, R.H., Wang, C.H., Mackenzie, C. and Cole, I. (2002). Durability design for wood construction. For. Prod. J. 52:10-19.

Fortino, S. (2017). Hygro-thermal models. In: Jones D, Brischke C (eds) Performance of Bio-based Building Materials. Elsevier:495-502.

Fortino, S., Genoese, A., Genoese, A., Nunes, L. and Palma, P. (2013). Numerical modelling of the hygro-thermal response of timber bridges during their service life: A monitoring case-study. Constr. Build. Mat. 47:12251234 .

Fragiacomo, M., Fortino, S., Tononi, D., Usardi, I. and Toratti, T. (2011). Moisture-induced stresses perpendicular to grain in timber sections exposed to European climates. Eng. Struct. 33:3071-3078.

Gellerich, A., Emmerich, L., Brischke, C., Meyer-Veltrup, L. and Kaudewitz, P. (2017). Evaluation of surface cracks on wood - physical assessment versus subjective sensation. Proc. IRG Ann. Meeting, IRG/WP 1720617.

Gobakken, L.R. (2009). Surface mould growth on painted and unpainted wood: influencing factors, modelling and aesthetic service life. PhD Thesis no. 2009:32. Norwegian University of Life Sciences.

Gobakken, L.R., Mattsson, J. and Alfredsen, G. (2008). In-service Performance of Wood Depends upon the Critical In-situ Conditions. Case Studies. Proc. IRG Ann. Meeting, IRG/WP 08-20382.

Hradil, P., Fortino, S., Salokangas, L., Musci, A and Metelli, G. (2016). Effect of moisture induced stresses on
the mechanical performance of glulam bdams of Vihantasalmi bridge. WCTE 22-25 Aug. 2016, Vienna.A
Austria
Humar, M., De Angelis, M., Romagnoli, M., Vek, V., Poljanšek, I., Oven, P., Thaler, N., Lesar, B. and Kržišnłk,
D. (2018). Material Resistance and Chemical Composition of Italian Stone Pine (Pinus pinea), Proc. IRG Ann.
Meeting, IRG/WP 18-20645.

Isaksson, T., Brischke, C. and Thelandersson, S. (2013). Development of decay performance models for outdoor

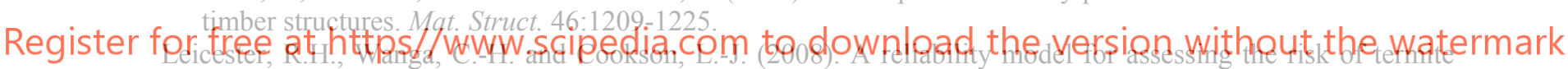
attack on housing in Australia. Reliab. Eng. Syst. Safety 93:468-475

MacKenzie, C.E., Wang, C.-H., Leicester, R.H., Foliente, G.C. and Nguyen, M.N. (2007). Timber service life guide. Forest and Wood Products Limited, Victoria.

Meyer-Veltrup, L., Brischke, C., Alfredsen, G., Humar, M., Flæte, P.O., Isaksson, T. and Jermer, J. (2017). The combined effect of wetting ability and durability on outdoor performance of wood: development and verification of a new prediction approach. Wood Sci. Technol. 51:615-637.

Niklewski, J., Fredriksson, M. and Isaksson, T. (2016). Moisture content prediction of rain-exposed wood: Test and evaluation of a simple numerical model for durability applications. Build. Environ. 97:126-136.

Pousette, A., Malo, K., Thelandersson, S., Fortino, S., Salokangas, L. and Wacker, J. (2017). Durable Timber Bridges - Final Report \& Guidelines. SP Report 25. RISE, Skellefteå, Sweden.

Sandak, A., Sandak, J., Dimitrou, A., Burud, I., Thiis, T., Gobakken, L.R., Ormondroyd, G.A. and Kraniotis, D. (2017). Assessment and monitoring of aesthetic appearance of building biomaterials along the service life. WIT Transactions on Ecology \& The Environment; Sustainable Development \& Planning 226:527-536

Sandak, J., Sandak, A. and Burud, I. (2017). Chapter 8.4. Modelling of weathering. In: Jones D, Brischke C (eds) Performance of Bio-based Building Materials. Elsevier: 502-510.

Tonini, F., Hochmair, H., Scheffrahn, R. and Deangelis, D. (2013). Simulating the Spread of an Invasive Termite in an Urban Environment Using a Stochastic Individual-Based Model. Environ. Entomol. 42:412

Viitanen, H., Toratti, T., Makkonen, L., Peuhkuri, R., Ojanen, T., Ruokolainen, L. and Räisänen, J. (2010). Towards modelling of decay risk of wooden materials. Eur. J. Wood Wood Prod. 68:303-313. 